\title{
28 Research Square \\ Normal coronary myocardial infarction due to COVID-19: A case series
}

\section{Erfan Kazemi}

Shahroud University of Medical Sciences https://orcid.org/0000-0002-3886-0466

Mehran Gheshlaghi

Shahroud University of Medical Sciences https://orcid.org/0000-0002-8564-5523

Ali Mansoursamaei

Shahroud University of Medical Sciences https://orcid.org/0000-0001-7206-2858

\section{Saba Homatash}

Shahroud University of Medical Sciences https://orcid.org/0000-0003-3450-1789

Hossein Sheibani ( $\boldsymbol{V}$ h1a1sheyban@gmail.com )

Shahroud University of Medical Sciences https://orcid.org/0000-0003-1632-0511

\section{Case Report}

Keywords: ST-elevation, Normal coronary, myocardial infarction, COVID-19, STEMI

Posted Date: January 25th, 2022

DOI: https://doi.org/10.21203/rs.3.rs-1286552/v2

License: (c) (1) This work is licensed under a Creative Commons Attribution 4.0 International License. Read Full License 


\section{Abstract}

Background: The prevalence of cardiovascular complications in COVID-19 infection varied in different studies. One of these complications is myocardial infarction. A disturbance of the blood supply can lead to myocardial infarction by clot formation in the arteries. However, no evidence of significant coronary stenosis has been found in more than $50 \%$ of patients with COVID-19 and ST elevation.

Case Presentation: 38 and 49 years old men (patients 1,2 ) were admitted to our hospital with the complaint of typical chest pain and COVID-19 symptoms. The real-Time Polymerase Chain Reaction (RTPCR) test confirmed COVID-19 in both. Patient 1 represented inferior posterior ST-Elevation Myocardial Infarction (STEMI) in his electrocardiogram (ECG). Also, patient 2 has ST-elevation in high lateral and septal leads (I, AVL, V1, V2) and ST-segment depression in AVR and inferior leads (III, AVF). Their troponin was positive. The vital signs were normal in both of them. Patient 2 just had a history of aortic valve replacement (AVR) 5 years ago. However, Patient 1 had no medical history. Transthoracic Echocardiography (TTE) data demonstrated some disturbances in patient 1 Severe hypokinesia of Inferior, Posterior, Lateral, and Septal walls. However, TTE data were unremarkable for patient 2. We prescribed recommended medications for them. Therefore, their ECG changes were corrected, and his condition improved. In addition, Coronary angiography was done that demonstrated patent and normal coronary arteries in both of them.

Conclusion: COVID-19 infection can cause normal coronary arteries myocardial infarction with probable two mechanisms prolonged vasospasm or intraluminal coronary thrombogenesis.

\section{Introduction}

From the beginning of the COVID-19 epidemic in December 2019, more than 15 million people get infected by COVID-19 until 26 July 2020 (1). COVID-19 pandemic causes a significant burden on medical institutions. In such a pandemic, the management of emergencies like Myocardial Infarction (MI) was too complicated (2). Cardiac risk factors expose the patients to more complex or clinical situations that require the Intensive Care Unit (ICU) (3). Myocardial injury due to ischemia, acute thrombotic obstruction, or myocarditis has been reported in approximately $7 \%$ to $28 \%$ of hospitalized patients with COVID- 19 . Studies have shown that these injuries are associated with increased mortality (4-6). Traditionally, STElevation Myocardial Infarction (STEMI) is the consequence of coronary artery stenosis. It means we can find some coronary arteries with an abnormal situation. We reported two patients with COVID-19 infection presented with STEMI and the normal coronary artery in these cases.

\section{Case Presentation}

\section{Case 1:}


A 38-years-old man complained of pain in the neck, chest, and right hand two days after taking azithromycin. He also had symptoms of COVID-19 such as fever, sore throat, weakness, and myalgia. As the pain intensified, he went to the hospital's emergency ward. The patient felt shortness of breath during the visit. But he had no fever, chills, cough, or sputum, and his heart rate was normal. As a result, real-time PCR was performed on him, and he was identified as a COVID-19 patient. His treatment was started according to the COVID-19 treatment protocol. The patient reported no history of cardiovascular and pulmonary diseases, thromboembolism, or coagulation. Also, he did not take any medication. On his arrival, physical examinations were performed; his $\mathrm{O}_{2}$ saturation was $100 \%$, blood pressure was $133 / 88$ $\mathrm{mmHg}$, and pulse rate was 85 beats per minute. The electrocardiography (ECG) showed inferior-posterior STEMI in interior ECG view (Fig 2A) and posterior ECG (Fig 2B). The laboratory results are shown in Table 1. Trans-Thoracic Echocardiography (TTE) study demonstrated Severe hypokinesia of Inferior, Posterior, Lateral, and Septal LV (Left Ventricle) walls with mild Mitral, Tricuspid, and Pulmonary valves regurgitation. LV ejection fraction and Systolic pulmonary pressure were estimated at $40 \%$ and $20 \mathrm{mmHg}$, respectively. Other acquired data from TTE were normal. Therefore, we hospitalized him in CCU with a diagnosis of COVID-19 and acute inferior-posterolateral MI. Treatment was begun including Atorvastatin, Aspirin, Plavix, Pantoprazole, Enoxaparin, Reteplase, and Nitroglycerin (TNG) with recommended doses in standard guidelines. His condition improved with these treatments, and ECG changes were corrected in anterior ECG (Fig 2C) and posterior ECG (Fig 2D). He underwent coronary angiography for rescue PCl (Percutaneous Coronary Intervention). Angiography was performed for him the next day, showing normal coronary vessels without any Intimal irregularity, atherosclerosis plaque, and thrombosis (Fig 1A). The patient was discharged with a good general condition and a normal examination.

\section{Case 2:}

A 49-year-old man was recently admitted to our hospital with the chief complaint of retrosternal typical chest pain, which released to the back and both hands and had started from 30 minutes before admission with a slowly increasing trend. He also had a headache, myalgia and lethargy, cough, dyspnea, and anorexia 48 hours ago, which can be the COVID-19 infection symptoms. He had a history of Aortic Valve Replacement (AVR) 5 years ago with good monitoring of INR (International Normalized Ratio). His blood pressure was $135 / 95 \mathrm{mmHg}$, and his heart rate was 85 regular beats per minute. 02 saturation was $96 \%$ without 02 therapy in room air. In the physical exam, he was aware and awake with good obey. The metallic valve sound was heard well. No rales and wheeze were heard in the lung exam. Spiral chest CTscan demonstrated widespread bilateral lesions in favor of Covid-19 pneumonia. The first electrocardiogram in the emergency room revealed sharp and typical ST-segment elevation in high lateral and septal leads (I, AVL, V1, V2) together with ST-segment depression in AVR and inferior leads (III, AVF) in favor of acute ischemia (Fig $3 A$ ).

TTE showed mild hypokinesia in the lateral wall with mild mitral regurgitation and good prosthetic aortic valve function. The first CBC showed leukopenia (WBC:3500) with normal diff. His INR was 2, and CRP was $2 \mathrm{mg} / \mathrm{L}$ (Table2). Immediately, we began anti-ischemic therapy containing ASA $300 \mathrm{mg}$, Plavix 300 $\mathrm{mg}$, atorvastatin $80 \mathrm{mg}$ stat, and TNG drip $5 \mu \mathrm{g} / \mathrm{min}$. Due to ST-segment elevation, the patient rapidly 
transferred to COVID-19 positive CCU for further evaluation and treatment of ECG changes, management of COVID-19, and maybe primary PCI. The first qualified troponin in the emergency room and the second 6 hours later was negative. In the second ECG after 20 minutes, TNG infusion chest pain was subsided almost entirely, and all ST elevation returned to baseline except in AVL (Fig 3B). Over time and with receiving TNG infusion, continued improvement course of symptoms and ECG changes resolving (Fig $3 C)$. After 2 hours, all ECG changes were corrected completely, and the patient was without any chest pain (Fig 3D). The third qualified troponin was weekly positive. Two days later, coronary angiography demonstrated complete patent and completely normal epicardial coronary arteries (Fig 1B). The patient was discharged after treatment of Covid-19 and improvement of other symptoms and signs with a calcium blocker, beta-blocker, and Warfarin.

\section{Discussion}

Cardiovascular complications have been reported in some COVID-19 cases. Frequently, myocardial injury has been seen between them (7). The prevalence of Cardiovascular disease among COVID-19 patients varies from $4 \%$ to $14.6 \%$. Therefore, it remained uncertain whether hypertension, diabetes mellitus, and cardiovascular disease are related to COVID-19 disease severity (2). Some studies reported COVID-19 cases with cardiac injuries such as pericarditis, myocarditis, arrhythmia, STEMI, and coronary artery thrombosis (8-11). The prevalence of myocardial infarction between women and men is $30 \%$ and $12 \%$, respectively. However, it was seen that in more than $50 \%$ of $\mathrm{MI}$, there isn't any evidence of obstructive coronary disease at the time of angiography $(12,13)$. There are some reasons for myocardial infarction with nonobstructive coronary arteries:1) prolonged coronary spasm can occlude the coronary artery and lead to myocardial infarction 2) coronary spam activates platelet and leads to acute coagulation process $(14,15) .3)$ Releasing emboli from enlarged and thrombotic cardiac chambers and transfer into coronary arteries. Some risk factors develop coronary vasospasm like cocaine, tobacco, and nicotine (16). Moderate to severe valvular heart disease and atrial fibrillation/flutter rhythm are important risk factors for coronary emboli. In this case that we presented, the patient had no history of atherothrombotic disorders or significant cardiovascular diseases, and his cardiac all chamber size was normal. In his ECG, acute Inferior-Posterior-Lateral STEMI was observed after treatment and angiography. Atherosclerosis plaque or intimal irregularity in the coronary arteries was not seen. According to our findings, there are two possibilities for the explanation of this event:

1) Some studies have reported that COVID-19 causes significant inflammation and coagulation, which is activated by an inflammatory response (17). In this patient, inflammatory factors were higher than normal; therefore, COVID-19 probably causes thrombus in the coronary artery and leads to acute InferiorPosterior-Lateral MI. Then, the patient use Reteplase to resolve this thrombus. Consequently, changes of ECG were corrected, and we didn't see any thrombus in angiography.

2) Our patient didn't use any drugs that cause prolonged spasms; therefore, COVID-19 probably leads to prolonged spasms in the coronary artery and finally acute MI. 
Regardless of myocardial infarction pathogenesis, we must note that COVID-19 infection can cause STelevation and $\mathrm{Ml}$, even in cases with normal coronary arteries and without any atherosclerosis plaque.

\section{Conclusion}

It appears that infection with COVID-19 can cause prolonged coronary artery spasm or clot formation in the arteries, which can eventually lead to myocardial infarction.

\section{Abbreviations}

COVID-19= coronavirus disease 2019

ACS $=$ Acute Coronary Syndrome

$E C G=$ Electrocardiogram

TTE= Trans-Thoracic Echocardiography

$\mathrm{MI}=$ Myocardial Infarction

STEMI= ST segment elevation myocardial infarction

\section{Declarations}

This study complies with the Declaration of Helsinki that the locally appointed ethics committee has approved the research protocol and that the subjects have obtained informed consent.

\section{Acknowledgments}

No fund was taken.

\section{Competing interests}

The authors declare that they have no competing interests.

\section{References}

1. World health organization. WHO; 2020 [Available from: https://www.who.int/docs/defaultsource/coronaviruse/situation-reports/20200725-covid-19-sitrep-187.pdf?sfvrsn=1 ede1410_2.

2. Kim HN, Lee JH, Park HS, Yang DH, Jang SY, Bae MH, et al. A Case of COVID-19 with Acute Myocardial Infarction and Cardiogenic Shock. J Korean Med Sci. 2020;35(27):e258-e.

3. Huang C, Wang Y, Li X, Ren L, Zhao J, Hu Y, et al. Clinical features of patients infected with 2019 novel coronavirus in Wuhan, China. The Lancet. 2020;395(10223):497-506. 
4. Guo T, Fan Y, Chen M, Wu X, Zhang L, He T, et al. Cardiovascular Implications of Fatal Outcomes of Patients With Coronavirus Disease 2019 (COVID-19). JAMA cardiology. 2020;5(7):1-8.

5. Shi S, Qin M, Shen B, Cai Y, Liu T, Yang F, et al. Association of Cardiac Injury With Mortality in Hospitalized Patients With COVID-19 in Wuhan, China. JAMA cardiology. 2020;5(7):802-10.

6. Wang D, Hu B, Hu C, Zhu F, Liu X, Zhang J, et al. Clinical Characteristics of 138 Hospitalized Patients With 2019 Novel Coronavirus-Infected Pneumonia in Wuhan, China. JAMA. 2020;323(11):10619.

7. Ong E, Castro-Dominguez Y, Brennan J, Oen-Hsiao J. COVID-19 complicated by ST-segment elevation myocardial infarction in a 29-year-old patient. Catheterization and Cardiovascular Interventions. 2020;n/a(n/a).

8. Dabbagh MF, Aurora L, D'Souza P, Weinmann AJ, Bhargava P, Basir MB. Cardiac Tamponade Secondary to COVID-19. JACC: Case Reports. 2020;2(9):1326.

9. Monmeneu JV, Dominguez Mafe E, Andres Soler J, Ventura Perez B, Solsona Caravaca J, Broseta Torres R, et al. Subacute perimyocarditis in a young patient with COVID-19 infection. European Heart Journal - Case Reports. 2020.

10. Dominguez-Erquicia P, Dobarro D, Raposeiras-Roubín S, Bastos-Fernandez G, Iñiguez-Romo A. Multivessel coronary thrombosis in a patient with COVID-19 pneumonia. European heart journal. 2020;41(22):2132.

11. Stefanini GG, Montorfano M, Trabattoni D, Andreini D, Ferrante G, Ancona M, et al. ST-Elevation Myocardial Infarction in Patients With COVID-19: Clinical and Angiographic Outcomes. Circulation. 2020;141(25):2113-6.

12. Reynolds HR, Srichai MB, Iqbal SN, Slater JN, Mancini GBJ, Feit F, et al. Mechanisms of myocardial infarction in women without angiographically obstructive coronary artery disease. Circulation. 2011;124(13):1414-25.

13. Gehrie ER, Reynolds HR, Chen AY, Neelon BH, Roe MT, Gibler WB, et al. Characterization and outcomes of women and men with non-ST-segment elevation myocardial infarction and nonobstructive coronary artery disease: results from the Can Rapid Risk Stratification of Unstable Angina Patients Suppress Adverse Outcomes with Early Implementation of the ACC/AHA Guidelines (CRUSADE) quality improvement initiative. Am Heart J. 2009;158(4):688-94.

14. Agewall S, Beltrame JF, Reynolds HR, Niessner A, Rosano G, Caforio ALP, et al. ESC working group position paper on myocardial infarction with nonobstructive coronary arteries. European heart journal. 2016;38(3):143-53. 
15. Nakayama N, Kaikita K, Fukunaga T, Matsuzawa Y, Sato K, Horio E, et al. Clinical features and prognosis of patients with coronary spasm-induced non-ST-segment elevation acute coronary syndrome. J Am Heart Assoc. 2014;3(3):e000795-e.

16. Gharacholou SM, ljioma N, Banwart E, Munoz FDC. ST-Segment Elevation Myocardial Infarction and Normal Coronary Arteries after Consuming Energy Drinks. Case Rep Cardiol. 2017;2017:4061205-.

17. Connors JM, Levy JH. COVID-19 and its implications for thrombosis and anticoagulation. Blood. 2020;135(23):2033-40.

\section{Tables}

Table 1: The results of serology laboratory assays done during CCU (coronary care unit) admission

\begin{tabular}{|lll|}
\hline Laboratory findings & Result & Normal range \\
\hline FBS (Fasting Blood Sugar) & 182 & Adult $(>20$ years): 70-115 \\
\hline CPK & $686 \mathrm{u} / \mathrm{I}$ & $\begin{array}{l}\text { Male:24-195 u/l } \\
\text { Female:24-170 u/l }\end{array}$ \\
\hline CPK-MB & $86 \mathrm{u} / \mathrm{I}$ & $<24 \mathrm{u} / \mathrm{I}$ \\
\hline Troponin I (1st time) & Positive weakly \\
Troponin I (2nd time) & Positive & \\
CPR & ++ & \\
\hline PT & 13 & $10.5-13.5$ \\
\hline PTT & 38 & $26-40$ \\
\hline
\end{tabular}

FBS: Fasting Blood Sugar, CPK: Creatine phosphokinase, CPK-MB: Creatine phosphokinase-MB, CRP: CReactive Protein, PT: Prothrombin Time, PTT: Partial Thromboplastin Time

Table 2: Laboratory findings measured during admission 


\begin{tabular}{|lll|}
\hline Laboratory findings & Result & Normal range \\
\hline FBS (blood sugar) & 102 & Adult ( $>20$ years): 70-115 \\
\hline CPK & $160 \mathrm{u} / \mathrm{I}$ & $\begin{array}{l}\text { Male:24-195 u/I } \\
\text { Female:24-170 u/I }\end{array}$ \\
\hline CPK-MB & & $<24 \mathrm{u} / \mathrm{l}$ \\
\hline Troponin I (1st time) & negative & Negative \\
Troponin I (2nd time) & negative & Negative \\
Troponin I (3rd time) & weekly positive & Negative \\
\hline CPR & $2 \mathrm{mg} / \mathrm{I}$ & $\leq 1 \mathrm{mg} / \mathrm{I}$ \\
\hline INR & $2 \mathrm{IU}$ & $\leq 1.5 I \mathrm{U}$ \\
\hline CBC & $3500 / \mathrm{mm} 3$ & $3500-10000 / \mathrm{mm} 3$ \\
\hline LDH & $724 \mathrm{IU} / \mathrm{L}$ & $313-618 \mathrm{IU} / \mathrm{L}$ \\
\hline PLT & $136000 / / \mathrm{mm} 3$ & $150000-450000 / \mathrm{mm} 3$ \\
\hline
\end{tabular}

FBS: Fasting Blood Sugar, CPK: Creatine phosphokinase, CPK-MB: Creatine phosphokinase-MB, CRP: CReactive Protein, INR: International Normalized Ratio, CBC: Complete Blood Count, LDH: Lactate Dehydrogenase, PLT: Platelet

\section{Figures}
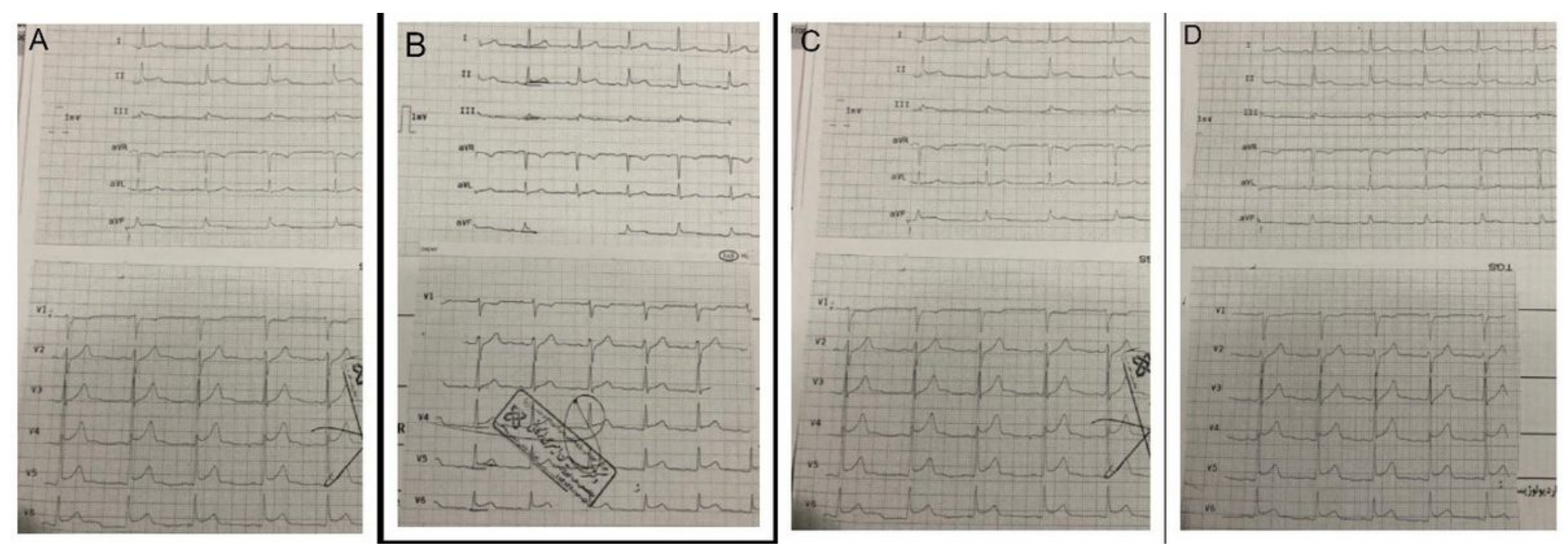

\section{Figure 1}

Electrocardiograms showing ST-segment elevations in Leads II, III, AFV, V4, V5, V6 (A), and posterior leads (B) that are diagnostic for acute inferior-posterior-lateral ST-elevation myocardial infarction (STEMI). 
Patient's corrected ECG after treatment in CCU anterior ECG (C) and posterior ECG (D).

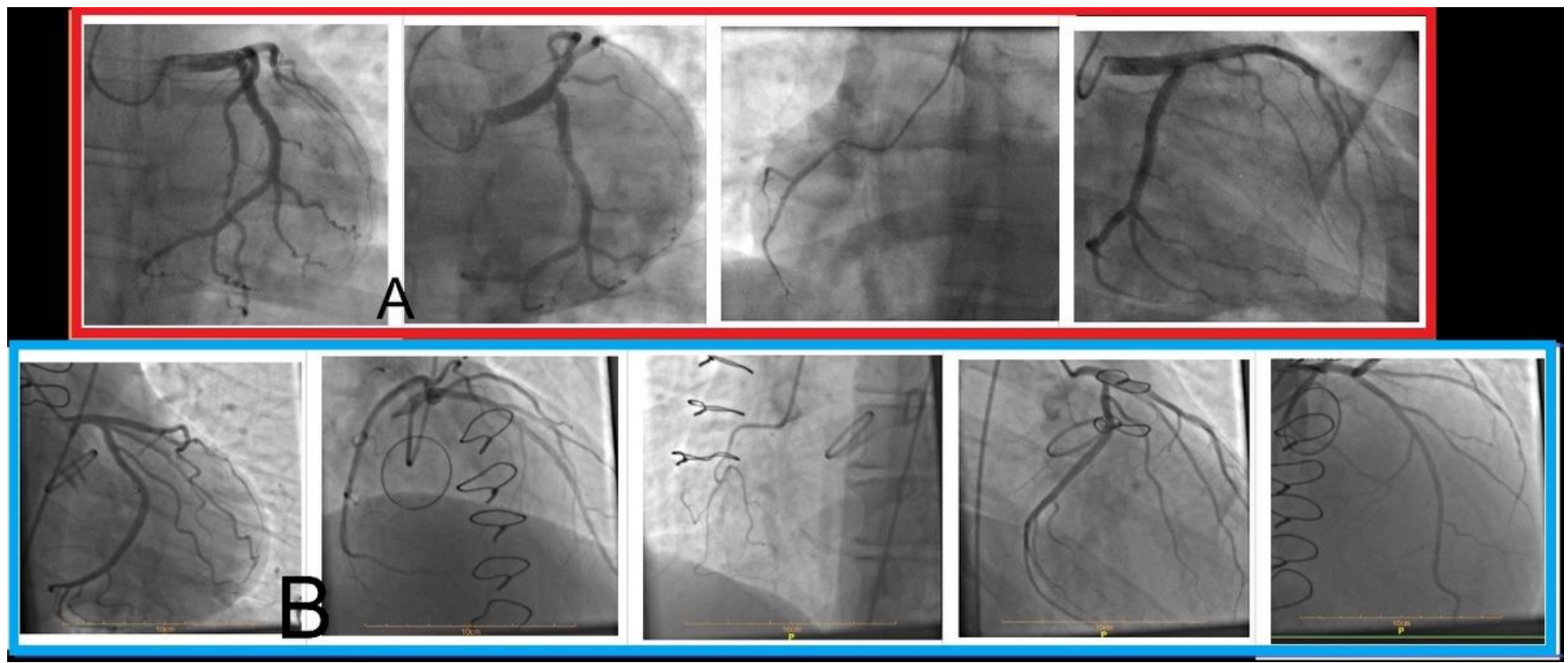

\section{Figure 2}

Selected coronary artery angiography images in different views that demonstrate patent coronary arteries (A). Images of the patient's coronary angiography in multiple views demonstrated patent and normal coronary arteries (B). (A row for case1, and B row for case2)
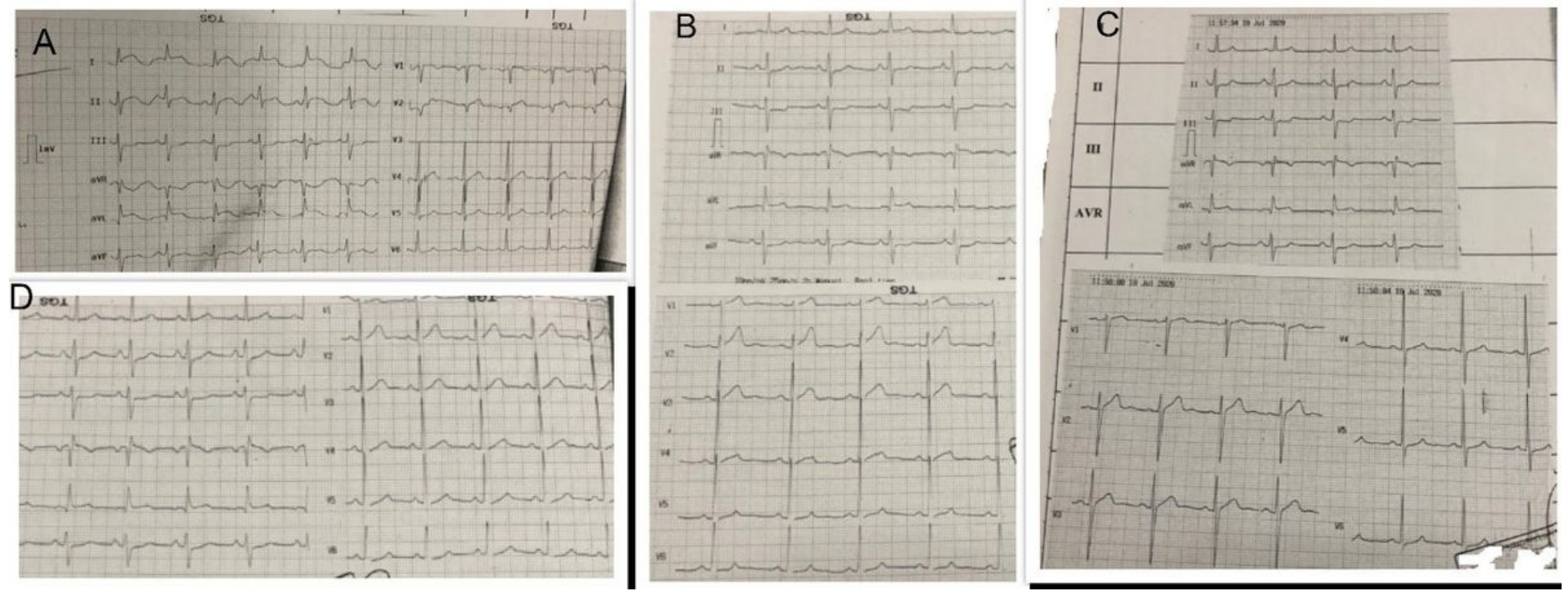

\section{Figure 3}

The first ECG in the emergency room demonstrated ST elevation in leads I, AVL, V5, V6 (A). The return of ST-segment elevation in all leads except in AVL by receiving TNG infusion. (B). More improvement of ECG changes by continuing TNG infusion (C). Complete disappearing of ST-segment changes in ECG (D) 

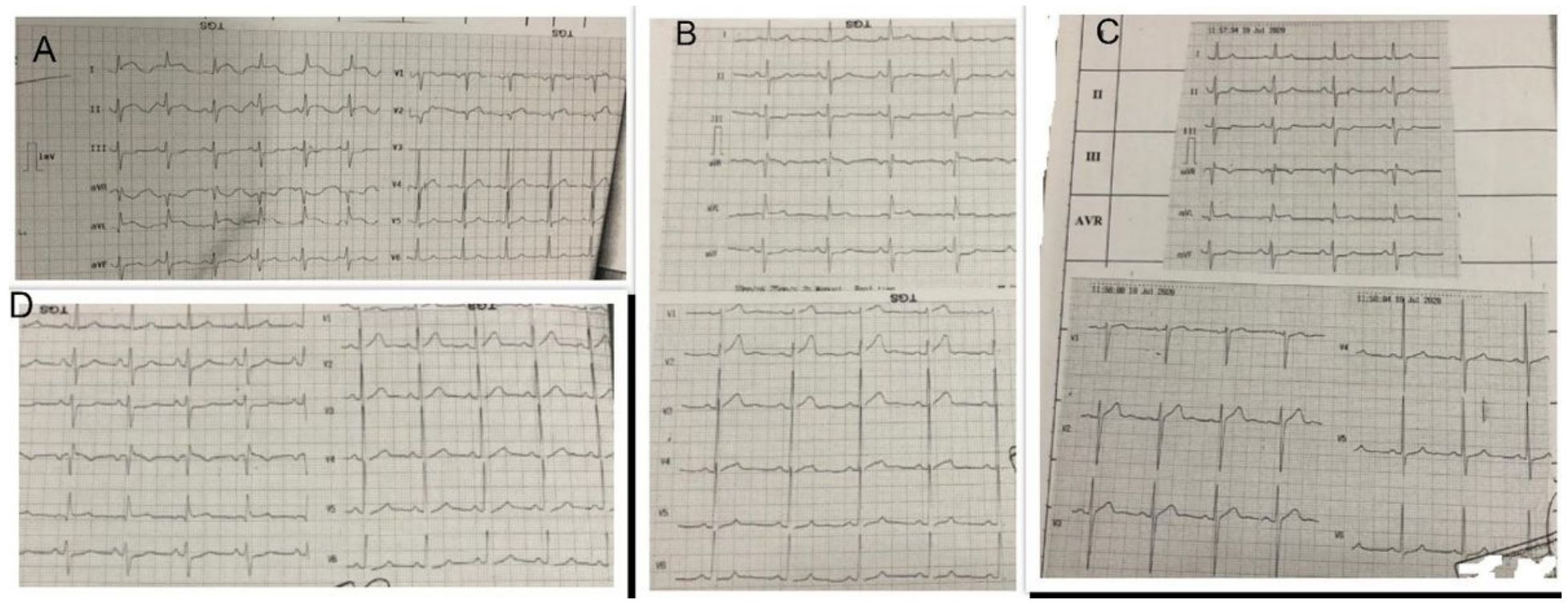

Figure 3

The first ECG in the emergency room demonstrated ST elevation in leads I, AVL, V5, V6 (A). The return of ST-segment elevation in all leads except in AVL by receiving TNG infusion. (B). More improvement of ECG changes by continuing TNG infusion (C). Complete disappearing of ST-segment changes in ECG (D) 